Research Article

\title{
Time-Varying Integral Adaptive Sliding Mode Control for the Large Erecting System
}

\author{
Xie Zheng, Xie Jian, Du Wenzheng, Li Liang, and Guo Yang \\ Xian High Technology Research Institute, Xian 710025, China \\ Correspondence should be addressed to Xie Zheng; xiez19891121@163.com
}

Received 22 May 2014; Revised 28 August 2014; Accepted 28 August 2014; Published 29 September 2014

Academic Editor: Chunlin Chen

Copyright (c) 2014 Xie Zheng et al. This is an open access article distributed under the Creative Commons Attribution License, which permits unrestricted use, distribution, and reproduction in any medium, provided the original work is properly cited.

\begin{abstract}
Considering the nonlinearities, uncertainties of large erecting system, and the circumstance disturbances in erecting process, a novel sliding mode control strategy is proposed in this research. The proposed control strategy establishes the sliding mode without reaching phase using an integral sliding surface. Thus, robustness against uncertainties increases from the very beginning of the process. Furthermore, adaptive laws are used for the controller to estimate the unknown but bounded system uncertainties. Therefore, the upper bounds of the system uncertainties are not required to be known in advance. Then, the time-varying term is applied to ensure the global robustness. Moreover, the boundary layer method is used to attenuate the high frequency chattering. The experiment results demonstrated that the proposed strategy could effectively restrain parametric uncertainties and external disturbances and improve the tracking accuracy in the erecting process. In addition, the control performance of the proposed control strategy is better than that of the PID control and the conventional sliding mode control.
\end{abstract}

\section{Introduction}

The large erecting system, as shown in Figure 1, is mainly used to erect and withdraw heavy equipment rapidly. It consists of erecting arm, proportional valve, erecting hydraulic cylinder, and a fixed base platform [1]. Generally, the electrohydraulic proportional control system is used as actuator to drive the erecting system. Due to the nonlinearities, uncertainties of the electrohydraulic proportional system, and the circumstance disturbances in erecting process, the conventional linear control methods cannot guarantee rapidity and stability in the erecting process. Controlling such uncertain systems is quite challengeable and has drawn much attention to the research community. Many researchers have used nonlinear control methods to compensate the nonlinear feature of erecting system. Firstly, the nonlinear predictive control technique was proposed in the previous research [2], while the system uncertainties are not taken into consideration. Thus, several kinds of intelligent control strategies were adopted in erecting systems by some researchers $[3,4]$. However, the results of these control strategies cannot overcome system uncertainties, especially the uncertainties out of uncertain parameters.
Sliding mode control (SMC) is a valid method for nonlinear system control. In recent years, SMC has been extensively applied to nonlinear control systems, such as motor control, robot control, and servo system control [5-8]. It has been successfully implemented to compensate the effects of the load variations [9], friction and internal leakage [10], and uncertain original volume [11]. However, the designed controller with SMC contains discontinuous function, which can cause chattering [12-14], so the performance of the control system is affected, and the SMC does not have robustness in the sliding mode. To achieve finite time convergence of system states, Choi proposed the time-varying sliding mode control [15], in which the time-varying sliding surface instead of the original sliding surface was used to make the sliding surface across the initial state at the initial moment. Reference [16] applied the time-varying sliding mode control to position control system, hydraulic servo system, and induction motor control. Metin et al. [17] presented sliding mode control with time-varying sliding surface for a class of nonlinear systems, which was transformed into a linear time invariant (LTI) system by frozen-time approach. Though simulation results show that the control strategy has global 


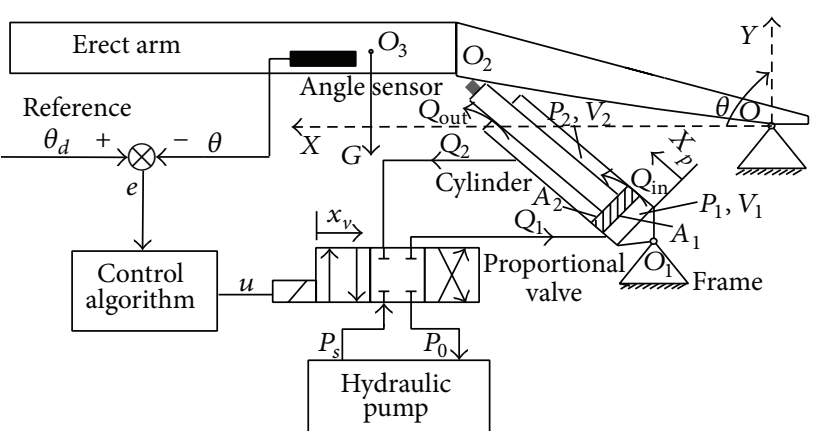

FIGURE 1: Schematic diagram of the erecting system.

stability, the robustness against the uncertainties and external disturbances was not discussed in Metin's research.

Motivated by the above discussions, we propose a timevarying integral adaptive sliding mode control strategy for the large erecting system which incorporates an integral sliding surface which eliminates the need for prior knowledge about the high order differential item of input signals and results in the elimination of reaching phase. In addition, the adaptive control law is introduced to guarantee robustness against the parametric uncertainties, unmodeled dynamics, and external disturbances. Moreover, the time-varying term is applied to ensure the system global robustness. The proposed control strategy has been experimentally implemented to control a hydraulic experimental platform of erecting system. The experimental results demonstrate the effectiveness of the proposed control strategy.

This research was organized as follows. In Section 2, the nonlinear model of the erecting system was presented. The main results on the design of the proposed time-varying integral adaptive sliding mode controller were given in Section 3. Experimental results were shown in Section 4 and conclusions were given in Section 5 .

\section{Mathematical Model of Erecting System}

Figure 1 shows that the erecting arm is driven by an electrohydraulic proportional control system (EPCS) and the erecting arm can be rotated around the joint $O$. The rotation angle of the erecting arm is controlled as follows: once the reference angle $\theta_{d}$ and the actual angle $\theta$ are transmitted to the controller, the output control signal $u$ is calculated with the control algorithm. Then, the valve spool position and direction are controlled by the signal $u$. The flow and the direction supplied to each cylinder chamber are determined based on the valve spool position. And the motion of the erecting arm actuated by the cylinder is controlled by the flow. To illustrate the motion of the erecting arm, a reference coordinate system $X O Y$ is established (see Figure 1). Let $O O_{1}=l_{1}, O O_{2}=l_{2}, O O_{3}=l_{4}$, and $\angle O O_{2} O_{1}=\alpha_{1}$, and at zero second let $\mathrm{O}_{1} \mathrm{O}_{2}=l_{3}, \angle O_{1} O O_{2}=\theta_{0}$, and $\angle X O O_{3}=\gamma$ where $\mathrm{O}_{3}$ is the center of gravity of the erecting arm. The EPCS of the erecting system is a valve controlled asymmetric hydraulic cylinder system, and its dynamic characteristics are different from those of the traditional symmetrical cylinder. The load flow and pressure need to be redefined in the process of modeling. The nonlinear model is composed of force balance equation, valve flow equation, and continuity equation of the cylinder volume [18].

2.1. Force Balance Equation for Piston. Based on Newton's second law, the force balance equation of the piston can be

$$
A_{1} P_{1}-A_{2} P_{2}=m \ddot{X}_{P}+B_{c} \dot{X}_{P}+K X_{P}+F_{L},
$$

where $A_{1}$ denotes the effective area of the head side of the piston, $A_{2}$ denotes the effective area of the rod side of the piston, $m$ denotes the equivalent mass of the cylinder, $B_{c}$ denotes the viscous damping coefficient, $K$ denotes the load spring gradient, and $P_{1}$ and $P_{2}$ denote the supply pressure and return pressure, respectively. The load which acted on the cylinder is mainly composed of inertia load. Since the spring gradient $K$ is very small, $K X_{P}$ is neglected in this research.

When the piston is moving in the steady state, (1) can be

$$
A_{1}\left(P_{1}-n P_{2}\right)=F_{L 0}
$$

where $n=A_{2} / A_{1}$, and $F_{L 0}$ represents the steady load force which acted on the piston. The load pressure can be defined as

$$
P_{L}=P_{1}-n P_{2}
$$

Based on the rotation differential equation law, the dynamics of the erecting arm are governed by

$$
J \ddot{\theta}=F_{L} l_{1} \sin \alpha_{1}-G l_{4} \cos (\gamma+\theta),
$$

where $J$ denotes the moment of inertia of the erecting arm, $F_{L}$ denotes the active force generated by the cylinder, $\theta$ denotes the erect angle, and $G$ denotes the gravity of the erecting arm. In the triangle $\mathrm{OO}_{1} \mathrm{O}_{2}$, the following equation can be derived based on the sine law:

$$
\frac{l_{1}}{\sin \alpha_{1}}=\frac{l_{3}+X_{P}}{\sin \left(\theta+\theta_{0}\right)},
$$

where $X_{P}$ denotes the displacement of the piston rod. In (4) and (5), active force $F_{L}$ can be written as

$$
F_{L}=\frac{J \ddot{\theta}+G l_{4} \cos (\gamma+\theta)}{l_{1} l_{2} \sin \left(\theta+\theta_{0}\right) /\left(l_{3}+X_{P}\right)} .
$$

2.2. Valve Flow Equation. The valve flow equation is a typical nonlinear equation. Since the effective piston area of the two sides is different, so the flow through the valve orifices is also different. Suppose that the spool valve is a symmetric valve, and the flow to the supply and return port of the valve is 
proportional to the spool displacement $x_{v}$. Then the flow of oil through the valve orifices can be written as

$$
\begin{gathered}
Q_{1}= \begin{cases}C_{d} w x_{v} \sqrt{\frac{2\left(P_{s}-P_{1}\right)}{\rho}} & x_{v} \geq 0 \\
C_{d} w x_{v} \sqrt{\frac{2 P_{1}}{\rho}} & x_{v}<0\end{cases} \\
Q_{2}= \begin{cases}C_{d} w x_{v} \sqrt{\frac{2 P_{2}}{\rho}} & x_{v} \geq 0 \\
C_{d} w x_{v} \sqrt{\frac{2\left(P_{s}-P_{2}\right)}{\rho}} & x_{v}<0,\end{cases}
\end{gathered}
$$

where $Q_{1}$ is the supplied flow rate to the forward chamber, $Q_{2}$ represents the returned flow rate of the backward chamber, $P_{s}$ is the supply line pressure, $C_{d}$ is the discharge coefficient of spool valve, $w$ is the spool valve area gradient, and $\rho$ is the oil mass density. Since a rapid response valve is used here, it is assumed that the spool displacement $x_{v}$ is proportional to the control signal $u$ (valve input control voltage), and then the following equation is given by $x_{v}=k_{p} u$, where $k_{p}$ is a positive proportional coefficient.

If the piston velocity is defined as $v$ in the steady state, $v=Q_{1} / A_{1}=Q_{2} / A_{2}$, and further $Q_{2} / Q_{1}=n$. Based on (6), (7), and (8), the pressures $P_{1}$ and $P_{2}$ can be written as

$$
\begin{aligned}
& P_{1}= \begin{cases}\frac{\left(n^{3} P_{S}+P_{L}\right)}{\left(n^{3}+1\right)} & x_{v} \geq 0 \\
\frac{\left(n P_{S}+P_{L}\right)}{\left(n^{3}+1\right)} & x_{v}<0\end{cases} \\
& P_{2}= \begin{cases}\frac{n^{2}\left(P_{s}-P_{L}\right)}{\left(n^{3}+1\right)} & x_{v} \geq 0 \\
\frac{\left(P_{s}-n^{2} P_{L}\right)}{\left(n^{3}+1\right)} & x_{v}<0 .\end{cases}
\end{aligned}
$$

Define the load flow as $Q_{L}=Q_{1}$ and substitute (9) into (7) and yield

$$
Q_{L}= \begin{cases}C_{d} w x_{v} \sqrt{\frac{2}{\rho} \frac{1}{1+n^{3}}\left(P_{s}-P_{L}\right)} & x_{v} \geq 0 \\ C_{d} w x_{v} \sqrt{\frac{2}{\rho} \frac{1}{1+n^{3}}\left(n P_{s}+P_{L}\right)} & x_{v}<0 .\end{cases}
$$

The valve coefficients can be obtained from differentiating equation (11).

The flow gain is

$$
K_{Q}=\frac{\partial Q_{L}}{\partial x_{v}}= \begin{cases}C_{d} w \sqrt{\frac{2}{\rho} \frac{1}{1+n^{3}}\left(P_{s}-P_{L}\right)} & x_{v} \geq 0 \\ C_{d} w \sqrt{\frac{2}{\rho} \frac{1}{1+n^{3}}\left(n P_{s}+P_{L}\right)} & x_{v}<0 .\end{cases}
$$

The flow-pressure coefficient is

$$
\begin{aligned}
K_{c} & =-\frac{\partial Q_{L}}{\partial P_{L}} \\
& = \begin{cases}\frac{-C_{d} w x_{v} \sqrt{2 / \rho\left(1+n^{3}\right)\left(P_{s}-P_{L}\right)}}{2\left(P_{s}-P_{L}\right)} & x_{v} \geq 0 \\
\frac{-C_{d} w x_{v} \sqrt{2 / \rho\left(1+n^{3}\right)\left(n P_{s}+P_{L}\right)}}{2\left(n P_{s}+P_{L}\right)} & x_{v}<0 .\end{cases}
\end{aligned}
$$

From (12) and (13), we can define the valve flow equation as

$$
Q_{L}=K_{Q} x_{v}-K_{c} P_{L}
$$

2.3. Continuity Equation of the Cylinder Volume. Assume that the pressures in each piston chamber are the same everywhere. Both the temperature and the density are constant. The continuity equation of the cylinder volume can be described as

$$
\begin{gathered}
Q_{1}=A_{1} \dot{X}_{P}+C_{\text {in }}\left(P_{1}-P_{2}\right)+\frac{V_{0}}{\beta_{e}} \dot{P}_{1} \\
Q_{2}=A_{2} \dot{X}_{P}+C_{\text {in }}\left(P_{1}-P_{2}\right)-C_{\text {out }} P_{2}-\frac{V_{0}}{\beta_{e}} \dot{P}_{2},
\end{gathered}
$$

where $\beta_{e}$ is the effective fluid bulk modulus, $V_{0}$ is the effective system oil volume, and $C_{\text {in }}$ and $C_{\text {out }}$ are the internal and external leakage coefficient of the cylinder, respectively.

Combine (9), (10), (15), and (16) to get

$$
\frac{Q_{1}+n Q_{2}}{\left(1+n^{2}\right)}=A_{1} \dot{X}_{P}+C_{t} P_{L}+\frac{V_{0}}{\beta_{e}\left(1+n^{2}\right)} \dot{P}_{L}+b P_{s} \text {, }
$$

where

$$
\begin{gathered}
C_{t}=\frac{1+n}{1+n^{3}} C_{\text {in }}+\frac{n^{3}}{\left(1+n^{3}\right)\left(1+n^{2}\right)} C_{\text {out }} \\
b=\frac{1+n}{1+n^{2}} b_{1} C_{\text {in }}-\frac{n}{1+n^{2}} b_{2} C_{\text {out }} ; \\
b_{1}=\frac{n^{3}-n^{2}}{1+n^{3}}, \quad b_{2}=\frac{n^{2}}{1+n^{3}} \quad x_{v} \geq 0 \\
b_{1}=\frac{n-1}{1+n^{3}}, \quad b_{2}=\frac{1}{1+n^{3}} \quad x_{v}<0 .
\end{gathered}
$$

The left part of (17) is

$$
\frac{Q_{1}+n Q_{2}}{\left(1+n^{2}\right)}=\frac{Q_{1}+n^{2} Q_{1}}{\left(1+n^{2}\right)}=Q_{1}=Q_{L} .
$$

Equation (17) is converted into

$$
Q_{L}=A_{1} \dot{X}_{P}+C_{t} P_{L}+\frac{V_{0}}{\beta_{e}\left(1+n^{2}\right)} \dot{P}_{L}+b P_{s} .
$$

Define the state variables $x=\left[\begin{array}{lll}x_{1} & x_{2} & x_{3}\end{array}\right]=$ $\left[\begin{array}{lll}X_{P} & \dot{X}_{P} & \ddot{X}_{P}\end{array}\right]$, where $x_{1}, x_{2}$, and $x_{3}$ represent the displacement, velocity, and acceleration of the piston rod, respectively. 
Based on (4), (6), (11), and (20), the system model can be expressed in a state-space form as

$$
\begin{gathered}
\dot{x}_{1}=x_{2} \\
\dot{x}_{2}=x_{3} \\
\dot{x}_{3}=a_{1} x_{2}+a_{2} x_{3}+\frac{g\left(x_{v}\right) u}{a_{3}}+a_{4}+F,
\end{gathered}
$$

where $F$ denotes the uncertain disturbance, and

$$
\begin{gathered}
a_{1}=-\frac{\beta_{e}\left(1+n^{2}\right)}{m V_{0}}\left(A_{1}^{2}+C_{t} B_{c}\right) ; \\
a_{2}=-\left(\frac{B_{c}}{m}+\frac{C_{t} \beta_{e}\left(1+n^{2}\right)}{V_{0}}\right) ; \\
a_{3}=\frac{m V_{0} / A_{1} \beta_{e}\left(1+n^{2}\right) C_{d} w k_{p}}{\sqrt{2 / \rho\left(1+n^{3}\right)}} ; \\
a_{4}=-\left(\frac{\dot{F}_{L}}{m}+\frac{C_{t} \beta_{e}\left(1+n^{2}\right)}{m V_{0}} F_{L}+\frac{A_{1}^{2} \beta_{e}\left(1+n^{2}\right)}{m V_{0}} b P_{s}\right) ; \\
g\left(x_{v}\right)= \begin{cases}\sqrt{\left(P_{s}-P_{L}\right)} & x_{v} \geq 0 \\
\sqrt{\left(n_{1} P_{s}+P_{L}\right)} & x_{v}<0 .\end{cases}
\end{gathered}
$$

\section{Time-Varying Integral Adaptive Sliding Mode Control for Erecting System}

Time-varying sliding mode control strategy is introduced based on accurate mathematical model, and it is suitable for the control of nonlinear system. However, the tracking control error will become greater if the actual system has parametric uncertainties, unmodeled dynamics, and external disturbances. Since the erecting system is a typical uncertain nonlinear system, a time-varying integral sliding surface and adaptive control laws are introduced to alleviate the above shortcomings.

After performing the Laplace transform, (1) and (16) can be rewritten as

$$
\begin{gathered}
A_{1} P_{L}=m X_{P} s^{2}+B_{c} X_{P} s+K X_{P}+F_{L}, \\
Q_{L}=A_{1} X_{P} s+C_{t} P_{L}+\frac{V_{0}}{\beta_{e}\left(1+n^{2}\right)} P_{L} s+b P_{s} .
\end{gathered}
$$

Based on (14), (23), and (24), the block diagram of the valve controlled asymmetric hydraulic cylinder system is shown in Figure 2.

Suppose that the desired angle signal is $\theta_{d}$ and the corresponding displacement of the piston rod is $X_{P d}$, in the triangle $\mathrm{OO}_{1} \mathrm{O}_{2}$; we have

$$
X_{P d}=\sqrt{l_{1}^{2}+l_{2}^{2}-2 l_{1} l_{2} \cos \left(\theta_{d}+\theta_{0}\right)}-l_{3} .
$$

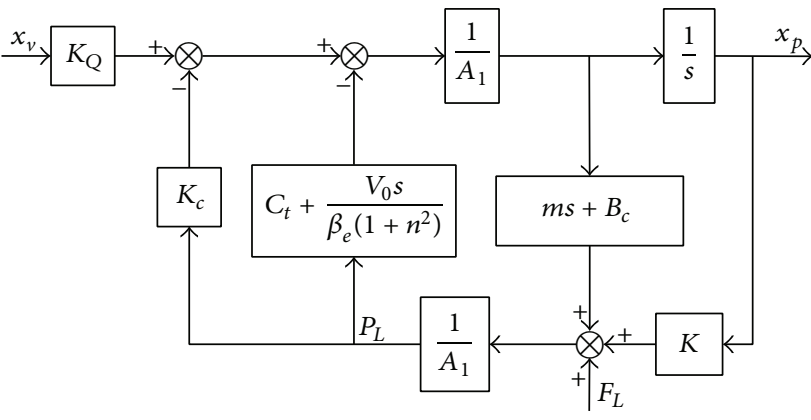

FIGURE 2: Block diagram of the valve controlled asymmetric hydraulic cylinder.

Similarly, the actual $\theta$ and $X_{P}$ have the following relationship:

$$
X_{P}=\sqrt{l_{1}^{2}+l_{2}^{2}-2 l_{1} l_{2} \cos \left(\theta+\theta_{0}\right)}-l_{3} .
$$

Control strategy is to control the angle $\theta$ to track the desired signal $\theta_{d}$ or the displacement $X_{P}$ to track the desired displacement signal $X_{P d}$ as closely as possible. For the real system, the following assumption is given.

Assumption 1. The desired position $X_{P d}(t)$, velocity $\dot{X}_{P d}(t)$, and acceleration $\ddot{X}_{P d}(t)$ are all bounded.

Definition 2. In system (21), if the input control signal is defined as (37) and the adaptive laws are chosen as (40), the system will be globally stable. In addition, tracking error of the system (21) will be convergent.

From the above analysis, the schematic diagram of timevarying integral adaptive sliding mode control is shown in Figure 3 with respect to the erecting system.

It can be found from Figure 3 that the controller is based on time-varying integral adaptive sliding mode control strategy. The controller consists of time-varying integral sliding mode control and adaptive control.

The time-varying integral sliding mode without reaching phase is established. The reaching phase is eliminated by using an integral surface and the chattering is reduced by using the concept of dynamic sliding mode control. We define the tracking error:

$$
z=x_{1}-x_{1 d} .
$$

The integral surface is given as

$$
s=c_{1} x_{1}+c_{2} x_{2}+x_{3}+k \int_{0}^{t} z d \tau+\varphi(t),
$$

where $c_{1}$ and $c_{2}$ are positive constants; $\varphi(t)$ denotes time varying item, which satisfies $t \rightarrow \infty$ and $\varphi \rightarrow 0$. Then, choose the exponential type surface, with $\varphi(t)=m_{1} e^{-t / n}$, where $e$ is Euler's number, $n$ is positive constant, and the smaller the $n$ is, the faster the convergence speed of the $\varphi(t)$ is. 


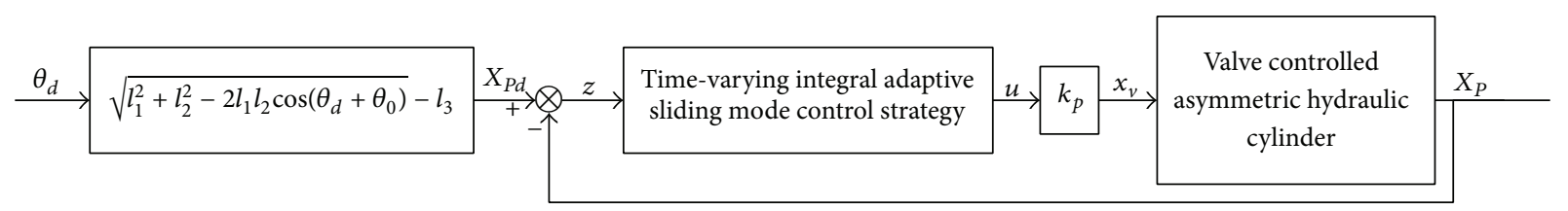

FIGURE 3: The schematic diagram of the time-varying integral sliding mode control.

To obtain the global robustness of sliding mode control, we make the sliding mode stay on the surface at initial states, namely, $s(t)=0, t=0$. Thus, the parameter $m_{1}$ is obtained:

$$
m_{1}=-c_{1} x_{1}(0)-c_{2} x_{2}(0)-x_{3}(0)-k \int_{0}^{t} z(0) .
$$

The derivative of (29) can be written as

$$
\dot{s}=c_{1} x_{2}+c_{2} x_{3}+\dot{x}_{3}+k z-\frac{m_{1}}{n} e^{-t / n}-k z(0) e^{-t / n} .
$$

Substituting (21) into (30), we have

$$
\begin{aligned}
\dot{s}= & c_{1} x_{2}+c_{2} x_{3}+\left(a_{1} x_{2}+a_{2} x_{3}+\frac{g\left(x_{v}\right) u}{a_{3}}+a_{4}\right) \\
& +k z-\left(\frac{m_{1}}{n}+k z(0)\right) e^{-t / n} .
\end{aligned}
$$

We define the following Lyapunov function:

$$
V_{1}=\frac{1}{2} a_{3} s^{2} \geq 0
$$

The derivative of (32) can be written as

$$
\begin{aligned}
& \dot{V}_{1}=s\left[c_{1} a_{3} x_{2}+c_{2} a_{3} x_{3}\right. \\
& +\left(a_{1} a_{3} x_{2}+a_{2} a_{3} x_{3}+g\left(x_{v}\right) u+a_{3} a_{4}\right. \\
& \left.\left.\quad+a_{3} k z-\left(\frac{a_{3} m_{1}}{n}+a_{3} k z(0)\right) e^{-t / n}\right)\right] .
\end{aligned}
$$
(33) as

Setting $\xi_{1}=a_{1} a_{3}, \xi_{2}=a_{2} a_{3}$, and $\xi_{3}=a_{3} a_{4}$, we can rewrite

$$
\begin{gathered}
\dot{V}_{1}=s\left[c_{1} a_{3} x_{2}+c_{2} a_{3} x_{3}\right. \\
+\left(\xi_{1} x_{2}+\xi_{2} x_{3}+g\left(x_{v}\right) u+\xi_{3}+a_{3} k z\right. \\
\left.\left.-\left(\frac{a_{3} m_{1}}{n}+a_{3} k z(0)\right) e^{-t / n}\right)\right] .
\end{gathered}
$$

Define $\widehat{\xi}_{1}, \widehat{\xi}_{2}, \widehat{\xi}_{3}, \widehat{a}_{3}$ as the online estimated value of $\xi_{1}$, $\xi_{2}, \xi_{3}, a_{3}$, respectively. And define $\widetilde{\xi}_{1}, \widetilde{\xi}_{2}, \widetilde{\xi}_{3}, \widetilde{a}_{3}$ as the online estimated value error of $\xi_{1}, \xi_{2}, \xi_{3}, a_{3}$, respectively. To obtain the update laws of parameters, we define a new Lyapunov function:

$$
V=\frac{1}{2}\left(a_{3} s^{2}+\lambda_{1} \tilde{\xi}_{1}^{2}+\lambda_{2} \tilde{\xi}_{2}^{2}+\lambda_{3} \tilde{\xi}_{3}^{2}+\lambda_{4} \tilde{a}_{3}^{2}\right) \geq 0 .
$$

The derivative of (35) can be written as

$$
\begin{aligned}
\dot{V}=s\left[c_{1} a_{3} x_{2}+c_{2} a_{3} x_{3}\right. & \\
& +\left(\xi_{1} x_{2}+\xi_{2} x_{3}+g\left(x_{v}\right) u+\xi_{3}+a_{3} k z\right. \\
& \left.\left.\quad-\left(\frac{a_{3} m_{1}}{n}+a_{3} k z(0)\right) e^{-t / n}\right)\right] \\
& +\lambda_{1} \widetilde{\xi}_{1}\left(-\dot{\bar{\xi}}_{1}\right)+\lambda_{2} \widetilde{\xi}_{2}\left(-\dot{\bar{\xi}}_{2}\right)+\lambda_{3} \widetilde{\xi}_{3}\left(-\dot{\bar{\xi}}_{3}\right)+\lambda_{4} \widetilde{a}_{3}\left(-\dot{\vec{a}}_{3}\right) .
\end{aligned}
$$

To ensure $s \dot{s} \leq 0$, the control law is chosen as

$$
\begin{aligned}
u= & {\left[\widehat{a}_{3}\left(-k z+\left(\frac{m_{1}}{n}+k z(0)\right) e^{-t / n}\right)\right.} \\
& \left.\quad-c_{1} \widehat{a}_{3} x_{2}-c_{2} \widehat{a}_{3} x_{3}-\widehat{\xi}_{1} x_{2}-\widehat{\xi}_{2} x_{3}-\widehat{\xi}_{3}-\varepsilon s-\eta \operatorname{sgn}(s)\right] \\
& \times\left(g\left(x_{v}\right)\right)^{-1},
\end{aligned}
$$

where $\varepsilon$ and $\eta$ are positive definite constants. The control law in (11) involves a discontinuous control sign function $\operatorname{sgn}(s)$, which leads to the practical issue of chattering due to its imperfections in switching devices and delays. In addition, the chattering causes oscillations of the control input around the sliding surface, thus the unwanted wear and tear of the actuators occur. To suppress the high-frequency chattering, continuous functions are often used in literatures to avoid the chattering of the control force and to achieve the exponential asymptotic stability. The saturation function sat $(s)$ rather than the sign function has been used to avoid chattering. The sat $(s)$ is expressed as

$$
\operatorname{sat}(s)= \begin{cases}1 & s>\Delta \\ s & |s| \leq \Delta \\ \Delta & s<-\Delta,\end{cases}
$$

where $\Delta$ is thickness of the boundary layer, and $\Delta>0$. 


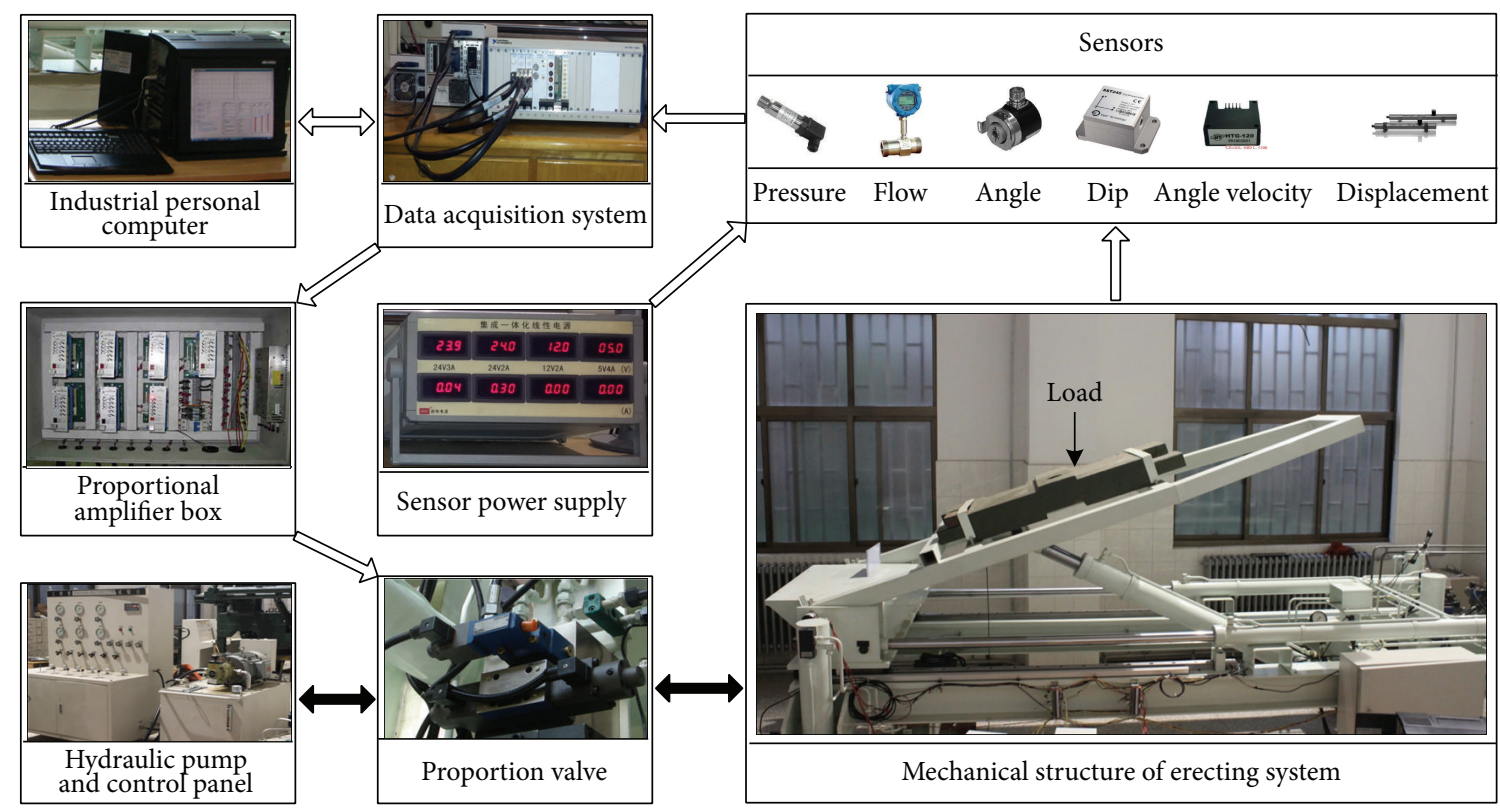

FIGURE 4: Hydraulic experimental platform of erecting system.

Substituting (37) into (36), we have

$$
\begin{aligned}
\dot{V}= & -\varepsilon s^{2}-\eta s \cdot \operatorname{sat}(s)+\widetilde{\xi}_{1}\left(s x_{2}-\lambda_{1} \dot{\vec{\xi}}_{1}\right) \\
& +\widetilde{\xi}_{2}\left(s x_{3}-\lambda_{2} \dot{\vec{\xi}}_{2}\right)+\widetilde{\xi}_{3}\left(s-\lambda_{3} \dot{\vec{\xi}}_{3}\right) \\
& +\tilde{a}_{3}\left[c_{1} s x_{2}+c_{2} s x_{3}+k s z\right. \\
& \left.-\left(\frac{a_{3} m_{1}}{n}+a_{3} k z(0)\right) e^{-t / n}-\lambda_{4} \dot{\hat{a}}_{3}\right] .
\end{aligned}
$$

To ensure $\dot{V}_{4} \leq 0$, the adaptive laws are chosen as

$$
\begin{gathered}
\dot{\vec{\xi}}_{1}=\frac{1}{\lambda_{1}} s x_{2} ; \\
\dot{\vec{\xi}}_{2}=\frac{1}{\lambda_{2}} s x_{3} ; \\
\dot{\vec{\xi}}_{3}=\frac{1}{\lambda_{3}} s \\
\dot{\hat{a}}_{3}=\frac{1}{\lambda_{4}}\left[c_{1} s x_{2}+c_{2} s x_{3}+k s z-\left(\frac{a_{3} m_{1}}{n}+a_{3} k z(0)\right) e^{-t / n}\right] .
\end{gathered}
$$

Substituting the above adaptive laws into (36), we have

$$
\dot{V}=-\varepsilon s^{2}-\eta s \cdot \operatorname{sat}(s) \leq 0 .
$$

From the above analysis, we find that the global asymptotic stability is guaranteed since $\dot{V} \leq 0$. And we design the time-varying integral sliding surface taking system initial value $s(0)=0$ into consideration, which implies $V(0)=0$ and $\dot{V}(0)=0$. Thus $V(t)$ and $s$ are equal to zero all the time; namely, the system trajectory stays on the sliding surface at any time. Hence, the reaching phase is eliminated and the system is robust against parameter uncertainties and external disturbances from the outset of the system operation.

Remark 3. From Assumption 1 and (41), it is clear that the Lyapunov function $V$ is bounded and $\lim _{t \rightarrow \infty} V=0$. According to the Lyapunov steady theory and Barbalat's lemma (Popov, 1973), the closed-loop system is globally steady and the tracking error $z$ approaches zero asymptotically, which is equal to $\lim _{t \rightarrow \infty} X_{P}(t)=X_{P d}(t)$ and $\lim _{t \rightarrow \infty} \theta(t)=\theta_{d}(t)$.

\section{Experimental Results}

The proposed control method was experimentally evaluated using the hydraulic experimental platform of erecting system (see Figure 4). The experimental platform is designed by Xi'an high-tech research institute and Zhejiang University and produced by Zhejiang University. The erecting arm is driven by hydraulic asymmetric cylinders with a piston diameter of $125 \mathrm{~mm}$, a rod diameter of $90 \mathrm{~mm}$, and a full stroke of $1480 \mathrm{~mm}$, which is controlled by a proportion valve (4WRA10E40-10B/24NZ4/M). The installed sensors measure the actuator lengths and pressures in both the rod and head sides of the pistons. The connection diagram of experimental platform is shown in Figure 5. The software development environment of experimental platform is based on LabWindows/CVI software and Matlab software. The proposed control strategy and compared counterpart are implemented in the software.

To test the effectiveness of the proposed time-varying integral adaptive sliding mode controller, the compared experiments are presented in this section. Firstly, the reference signal should be confirmed. Considering the capability of the hydraulic system in the actual erecting system, we 


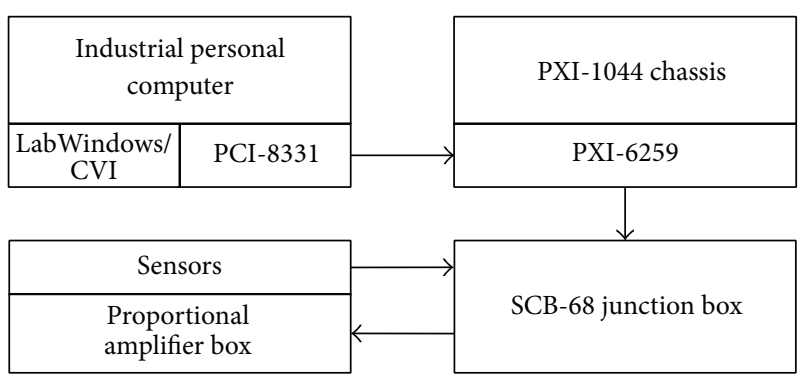

Figure 5: The connection diagram of experimental table.
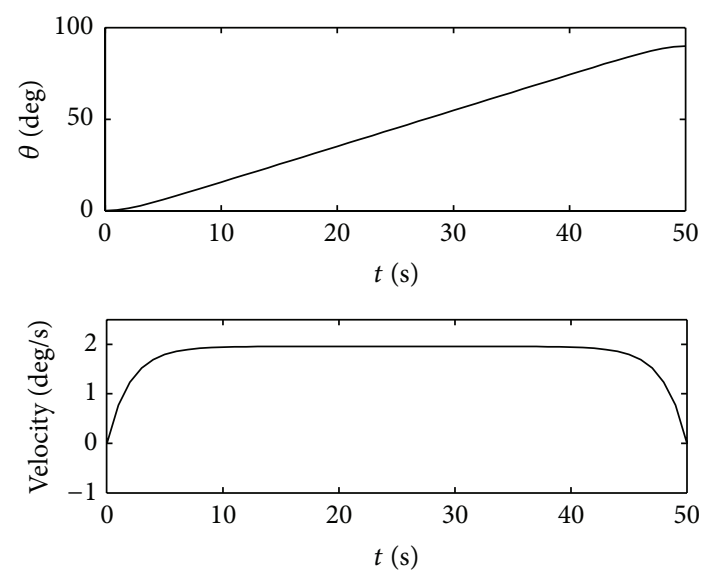

Figure 6: Desired angle and velocity curves.

have planned the desired erect angle and velocity curves (see Figure 6). The erect angle changes from 0 degrees to 90 degrees within 50 seconds.

From (23), the desired displacement curve of the piston $\operatorname{rod} X_{P d}(t)$ can be obtained. Table 1 shows the main original parameters in the real erecting system, while some of them are uncertain and hard to confirm because of the external disturbances and environment changes.

The following assumptions are to study the influence from the uncertain parameters and to test the performance of the proposed control scheme. Supposing the damping coefficient $B_{c}$, bulk modulus $\beta_{e}$, mass of the erecting $\operatorname{arm} M$, and the uncertain disturbance $F$, we have the following expression:

$$
\begin{gathered}
B_{c}=B_{c 0}+0.04 B_{c 0} \sin (0.1 \pi t), \\
\beta_{e}=\beta_{e 0}+0.01 \beta_{e 0} \sin (0.1 \pi t), \\
M=M_{0}+0.09 M_{0} \sin (0.1 \pi t), \\
F=4000 \sin (0.1 \pi t),
\end{gathered}
$$

where $B_{c 0}, \beta_{c 0}$, and $M_{0}$ are the original values and the other parts are the parameter uncertainties. Therefore, the parameters $a_{1}, a_{2}, a_{3}, a_{4}, \xi_{1}, \xi_{2}$, and $\xi_{3}$ of the system are uncertain.
The parameters of the proposed controller are designed as $c_{1}=90 ; c_{2}=2700 ; k=2.7 \times 10^{4} ; \varepsilon=2000 ; \eta=0.5 ; n=0.002$; $\Delta=0.2 ; \lambda_{1}=1.2 \times 10^{-9} ; \lambda_{2}=0.01 ; \lambda_{3}=1.2$; and $\lambda_{4}=0.001$.

Here, two control methods (the PID control and the conventional SMC) are used to compare their control performance. The control law of the PID control can be expressed as

$$
u_{1}(t)=k_{p} e(t)+k_{i} \int e(t) d t+k_{d} \dot{e}(t)
$$

where $k_{p}$ is the proportional coefficient, $k_{i}$ is the integral coefficient, $k_{d}$ is derivative coefficient, and $k_{p}=8, k_{i}=4$, and $k_{d}=0.005$, respectively.

The control law of the conventional SMC can be expressed as

$$
\begin{aligned}
& u_{2}(t) \\
& =\frac{\left[k_{1} e_{2}+k_{2} e_{3}+\dddot{x}_{1 d}-a_{1} x_{2}-a_{2} x_{3}-a_{4}+k s+\varepsilon \operatorname{sgn}(s)\right]}{\left(a_{3} g\left(x_{v}\right)\right)},
\end{aligned}
$$

where $k_{1}=2.9 \times 10^{7}, k_{2}=10800, \varepsilon=5000, k=3000, s=$ $k_{1} e_{1}+k_{2} e_{2}+e_{3}, e_{1}=x_{1 d}-x_{1}, e_{2}=\dot{x}_{1 d}-x_{2}$, and $e_{3}=\ddot{x}_{1 d}-x_{3}$.

The control strategies are implemented in the MAT$\mathrm{LAB} /$ Simulink software and the sample time $\tau=0.1 \mathrm{~s}$. Applying the above three controllers to track the desired angle curve under the condition that the system has parametric uncertainties and external disturbances, we get satisfied results. Figures $7(\mathrm{a}), 8(\mathrm{a})$, and 9 (a) present the simulation results, while the other figures show the experimental results.

Figure 7 exhibits the angle tracking curves of the three controllers and Figure 8 presents their angle tracking error curves. From Figures $7(\mathrm{a})$ and $7(\mathrm{~b})$, it can be seen that the proposed time-varying integral adaptive sliding mode controller has the best tracking precision and shows steadier and more accurate performance compared to the other two controllers. In Figure 8(a), the maximum tracking error of the proposed controller is 0.159 degrees at about 0.4 seconds, and the maximum tracking error of the PID control method is 1.131 degrees and 0.691 degrees for the conventional SMC. Moreover, in the erecting progress, tracking error of the proposed controller fluctuates within a smaller range and the error is 0.0891 degrees at 50 seconds. However, the other two controllers have distinct vibration because of the parametric uncertainties and external disturbances. And the PID controller has an error about 0.7491 degrees at the 50th second. Meanwhile, from the experimental result in Figure 8(b), we can obtain the same conclusion from the simulation results of Figure 8(a).

Figure 9 shows the control signal of the three controllers. As can be seen in Figure 9(a), the curve of the proposed controller is smoother than that of the other two controllers, since the adaptive laws can compensate the parameters uncertainties. However, the other two curves have vibration under the influence of the parametric uncertainties and external disturbances. Furthermore, in order to realize good performance, it must increase the value of the parameter $\varepsilon$ for the conventional SMC. However, this will lead to chattering of 
TABLE 1: Parameters of the erecting system.

\begin{tabular}{|c|c|c|c|c|c|c|c|}
\hline \multicolumn{3}{|c|}{ Parameters } & Symbols & & Values & & Units \\
\hline \multicolumn{3}{|c|}{ Supply pressure } & $P_{S}$ & & 18 & & $\mathrm{MPa}$ \\
\hline \multicolumn{3}{|c|}{ Discharge coefficient of the spool valve } & $C_{d}$ & & 0.62 & & - \\
\hline \multicolumn{3}{|c|}{ Area gradient of the spool valve } & $w$ & & $2.51 \times 10^{-2}$ & & $\mathrm{~m}$ \\
\hline \multicolumn{3}{|c|}{ Bulk modulus of the oil } & $\beta_{e 0}$ & & $7.5 \times 10^{8}$ & & $\mathrm{~Pa}$ \\
\hline \multicolumn{3}{|c|}{ Length of the piston rod } & $l$ & & 1.5935 & & $\mathrm{~m}$ \\
\hline \multicolumn{3}{|c|}{ Equivalent viscous damping coefficient } & $B_{c 0}$ & & 800 & & $\mathrm{~N} / \mathrm{m} / \mathrm{s}$ \\
\hline \multicolumn{3}{|c|}{ Mass density of the oil } & $\rho$ & & 868 & & $\mathrm{Kg} / \mathrm{m}^{3}$ \\
\hline \multicolumn{3}{|c|}{ Equivalent mass of the cylinder } & $m$ & & 178.31 & & $\mathrm{Kg}$ \\
\hline \multicolumn{3}{|c|}{ Inwards leakage coefficient of the cylinder } & $C_{\text {in }}$ & & $2.41 \times 10^{-11}$ & & $\mathrm{~m}^{3} / \mathrm{s} * \mathrm{~Pa}$ \\
\hline \multicolumn{3}{|c|}{ Outwards leakage coefficient of the cylinder } & $C_{\text {out }}$ & & $7.1 \times 10^{-13}$ & & $\mathrm{~m}^{3} / \mathrm{s} * \mathrm{~Pa}$ \\
\hline \multicolumn{3}{|c|}{ Equivalent mass of the erecting arm } & $M_{0}$ & & 1155.98 & & $\mathrm{Kg}$ \\
\hline \multicolumn{3}{|c|}{ Moment of inertia of the erecting arm } & $J$ & & 10023 & & $\mathrm{Kg} * \mathrm{~m}^{2}$ \\
\hline \multicolumn{3}{|c|}{ Section area of piston side/rod side } & $A_{1} / A_{2}$ & & $0.0175 / 0.0133$ & & $\mathrm{~m}^{2}$ \\
\hline \multicolumn{3}{|c|}{ Internal volume of the chamber } & $V_{0}$ & & $1.5 \times 10^{-5}$ & & $\mathrm{~m}^{3}$ \\
\hline \multicolumn{3}{|c|}{ Length of $\mathrm{OO}_{1} / \mathrm{OO}_{2} / \mathrm{O}_{1} \mathrm{O}_{2} / \mathrm{OO}_{3}$} & $l_{1} / l_{2} / l_{3} / l_{4}$ & & $1.132 / 1.62 / 1.032 / 3$ & & $\mathrm{~m}$ \\
\hline \multicolumn{3}{|c|}{ Angle of $\angle \mathrm{OlOO}_{2} / \angle \mathrm{XOO}_{3}$ at $0 \mathrm{~s}$} & $\theta_{0} / \gamma$ & & $0.6816 / 0.1047$ & & $\mathrm{rad}$ \\
\hline & & & TABLE & & & & \\
\hline \multirow{2}{*}{ Time/s } & \multicolumn{4}{|c|}{ Angle/degree } & \multicolumn{3}{|c|}{ Control signal/V } \\
\hline & Reference value & TVIASMC & PID & SMC & TVIASMC & PID & SMC \\
\hline 2 & 1.439 & 1.469 & 0.536 & 1.160 & 1.788 & 1.282 & 1.978 \\
\hline 2.1 & 1.565 & 1.551 & 0.863 & 1.305 & 1.857 & 1.374 & 1.867 \\
\hline 2.2 & 1.694 & 1.769 & 0.879 & 1.198 & 1.924 & 1.466 & 1.782 \\
\hline 2.3 & 1.826 & 1.791 & 0.877 & 1.412 & 1.987 & 1.558 & 1.736 \\
\hline 2.4 & 1.961 & 1.980 & 1.099 & 1.614 & 2.047 & 1.649 & 1.738 \\
\hline 2.5 & 2.099 & 2.156 & 1.242 & 1.546 & 2.104 & 1.740 & 1.794 \\
\hline 2.6 & 2.241 & 1.938 & 1.497 & 1.999 & 2.158 & 1.829 & 1.900 \\
\hline 2.7 & 2.384 & 2.465 & 1.385 & 1.962 & 2.209 & 1.917 & 2.052 \\
\hline 2.8 & 2.530 & 2.353 & 1.487 & 2.020 & 2.258 & 2.004 & 2.239 \\
\hline 2.9 & 2.679 & 2.690 & 1.593 & 2.318 & 2.305 & 2.089 & 2.446 \\
\hline 3 & 2.830 & 2.867 & 1.583 & 2.394 & 2.349 & 2.172 & 2.654 \\
\hline 3.1 & 2.983 & 2.731 & 1.965 & 2.513 & 2.391 & 2.254 & 2.850 \\
\hline 3.2 & 3.138 & 3.069 & 1.847 & 2.580 & 2.430 & 2.333 & 3.013 \\
\hline 3.3 & 3.295 & 3.581 & 2.171 & 2.621 & 2.468 & 2.410 & 3.134 \\
\hline 3.4 & 3.454 & 3.401 & 2.321 & 2.853 & 2.505 & 2.486 & 3.204 \\
\hline 3.5 & 3.615 & 3.662 & 2.587 & 3.039 & 2.539 & 2.558 & 3.217 \\
\hline 3.6 & 3.777 & 3.836 & 2.383 & 3.304 & 2.571 & 2.628 & 3.176 \\
\hline 3.7 & 3.942 & 4.117 & 2.915 & 3.479 & 2.603 & 2.697 & 3.087 \\
\hline 3.8 & 4.108 & 4.281 & 2.937 & 3.499 & 2.632 & 2.762 & 2.963 \\
\hline 3.9 & 4.274 & 4.251 & 3.028 & 3.821 & 2.660 & 2.824 & 2.818 \\
\hline 4 & 4.442 & 4.469 & 3.329 & 3.968 & 2.687 & 2.884 & 2.668 \\
\hline 4.1 & 4.613 & 4.706 & 3.530 & 4.054 & 2.713 & 2.942 & 2.532 \\
\hline 4.2 & 4.783 & 4.819 & 3.643 & 4.137 & 2.737 & 2.997 & 2.423 \\
\hline 4.3 & 4.956 & 5.227 & 3.721 & 4.490 & 2.761 & 3.049 & 2.355 \\
\hline 4.4 & 5.130 & 5.163 & 4.174 & 4.556 & 2.783 & 3.099 & 2.336 \\
\hline 4.5 & 5.303 & 5.309 & 4.260 & 4.637 & 2.805 & 3.146 & 2.371 \\
\hline 4.6 & 5.479 & 5.331 & 4.359 & 4.935 & 2.826 & 3.191 & 2.457 \\
\hline 4.7 & 5.656 & 5.440 & 4.745 & 5.136 & 2.846 & 3.233 & 2.588 \\
\hline 4.8 & 5.833 & 5.814 & 4.854 & 5.110 & 2.865 & 3.273 & 2.750 \\
\hline 4.9 & 6.011 & 5.887 & 4.888 & 5.618 & 2.883 & 3.310 & 2.932 \\
\hline 5 & 6.191 & 6.155 & 5.275 & 5.392 & 2.901 & 3.345 & 3.115 \\
\hline
\end{tabular}




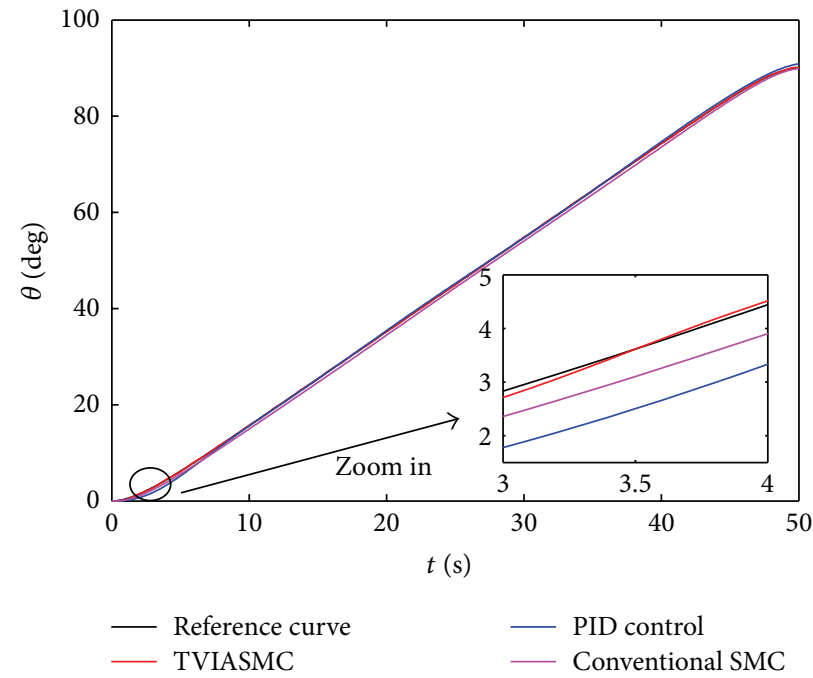

(a)

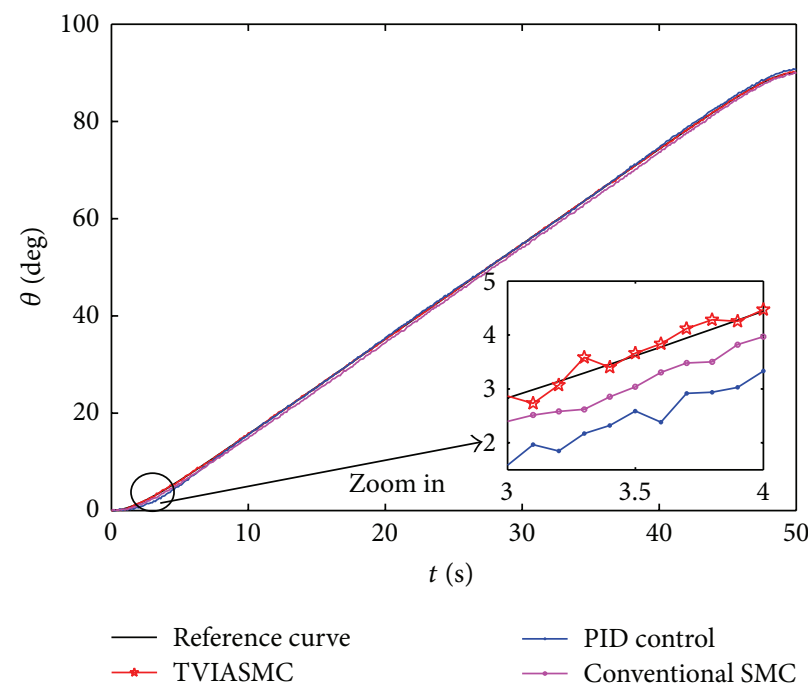

(b)

FIGURE 7: Angle tracking curves.

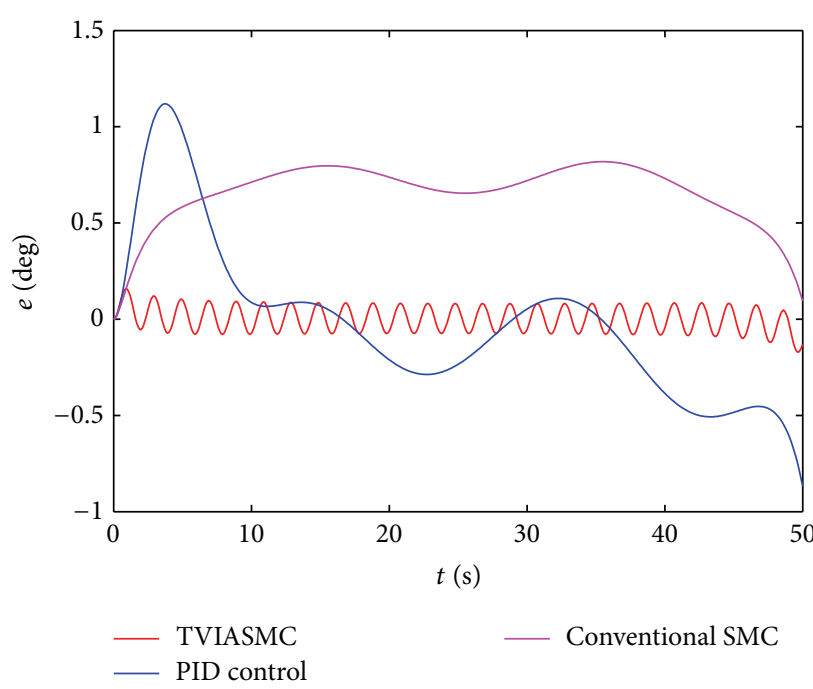

(a)

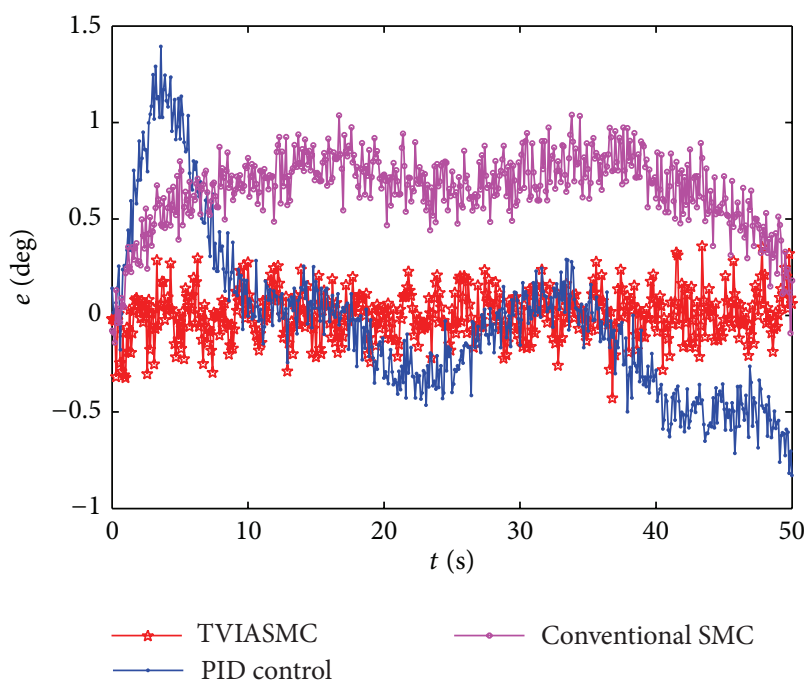

(b)

FIgURE 8: Angle tracking error curves.

the control signal with high frequency and make the erecting process unstable. Similarly, from the experimental result in Figure 9(b), we can obtain the same conclusion from the simulation results of Figure 9(a).

Figures 10 and 11 present the parameters estimation results. It can be seen that all the parameters are bounded and the parameters' real-time updating improves the tracking performance during the control process.

\section{Conclusions}

A time-varying integral adaptive sliding mode control strategy for the erecting system is proposed to realize trajectory tracking control in this research. The erecting system consists of mechanism, electrical equipment, and hydraulic actuator, which has strong nonlinearities and uncertainties. Therefore, the conventional control strategies are not valid for these rather complicated nonlinear systems. Combining with the advantages of time-varying integral sliding mode control and adaptive control law, we proposed a time-varying integral adaptive sliding mode control strategy in this research. The proposed control strategy can guarantee robustness against the parametric uncertainties and external disturbances. The results show that the proposed control strategy can obtain excellent angle tracking performance and realize nonlinear robust control. 


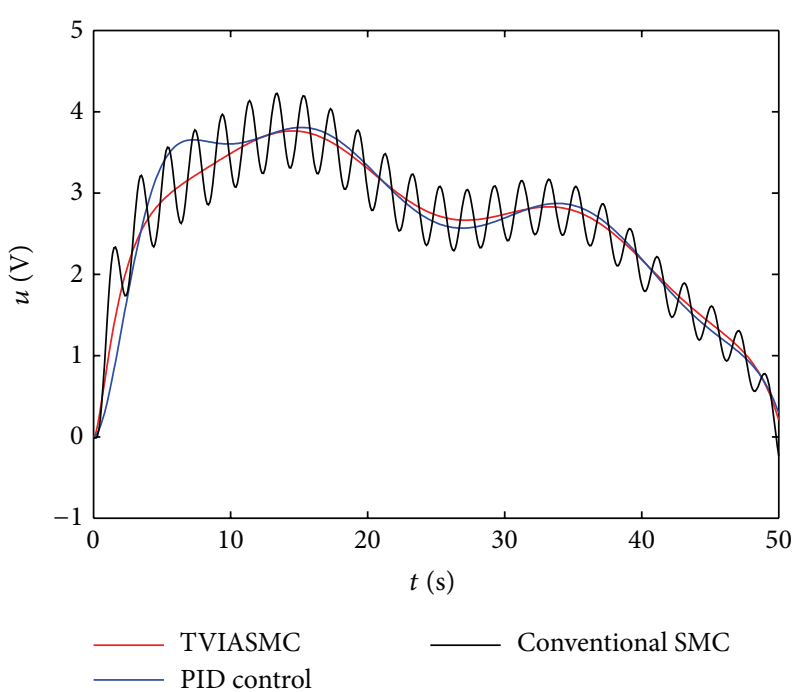

(a)

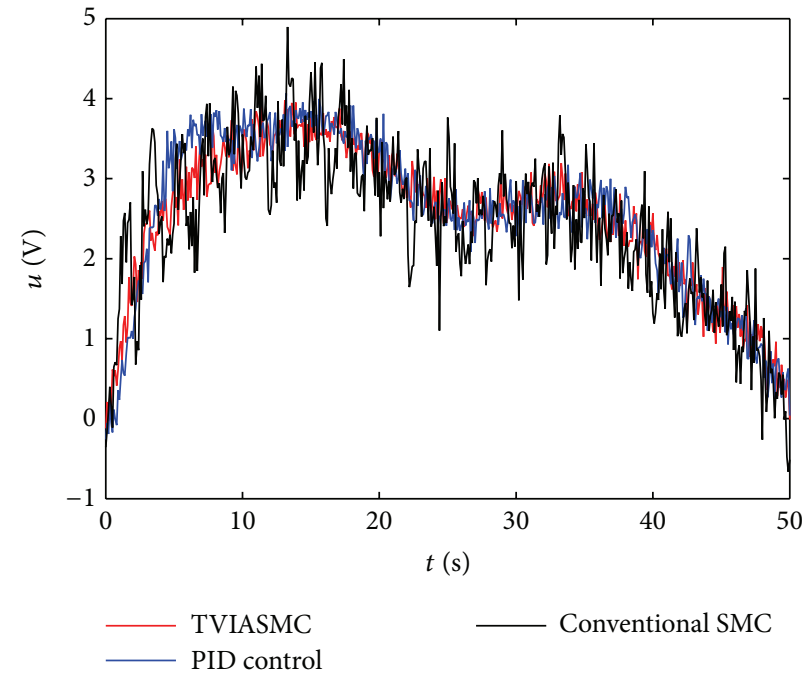

(b)

FIgURE 9: Control signal curves.
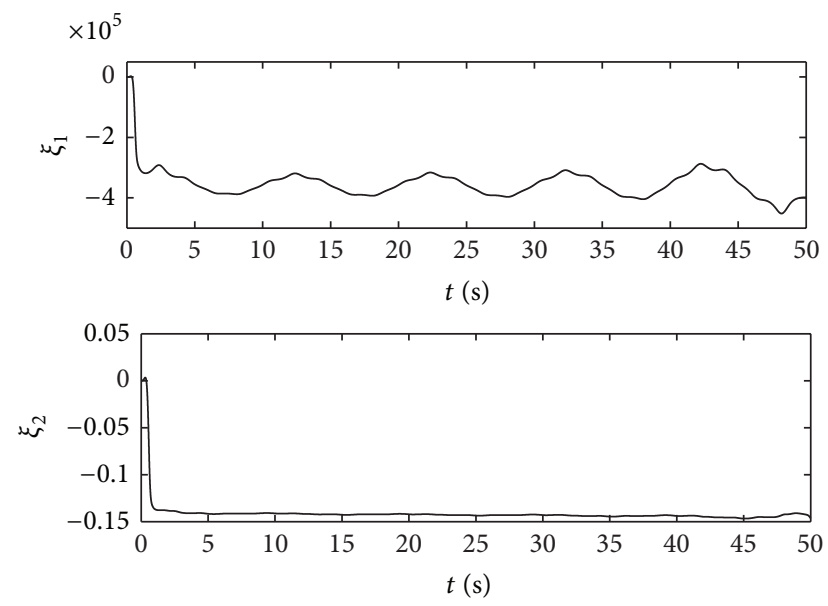

Figure 10: Parameter $\xi_{1}$ and $\xi_{2}$ estimations.

\section{Appendix}

In this appendix, because the amount of the real experiments data is very large (there are 501 values for every parameter), only some subsets of the real experiments data are given as shown in Table 2.

\section{Conflict of Interests}

The authors declare that there is no conflict of interests regarding the publication of this paper.
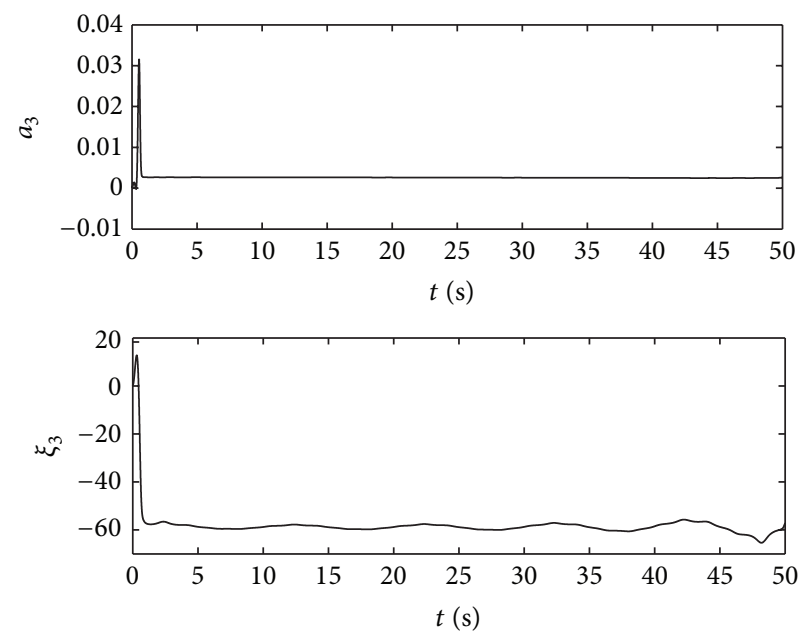

FIGURE 11: Parameter $\xi_{3}$ and $a_{3}$ estimations.

\section{Acknowledgment}

This work was partially supported by National Natural Science Foundation of China (61304239).

\section{References}

[1] X. G. Yao, X. S. Guo, Y. B. Feng et al., "Dynamic simulation for missile erection system," Journal of China Ordnance, vol. 3, no. 4, pp. 262-267, 2007.

[2] C. Q. Yu, X. S. Guo, and C. L. Ma, "Non-linear predictive control in the process of missile erecting," Acta Armamentar II, vol. 29, no. 11, pp. 1400-1404, 2008.

[3] C. L. Ma, X. X. Huang, and F. Li, "Simulation study of intelligent control for large mechanism erection system," Acta Armamentarii, vol. 29, no. 2, pp. 227-231, 2008. 
[4] J. Xie and G. Tian, "Erecting process control and simulation of large-scale electromechanical equipment," Journal of System Simulation, vol. 20, no. 23, pp. 6438-6441, 2008.

[5] S.-J. Huang and W.-C. Lin, "Adaptive fuzzy controller with sliding surface for vehicle suspension control," IEEE Transactions on Fuzzy Systems, vol. 11, no. 4, pp. 550-559, 2003.

[6] B. S. Park, S. J. Yoo, J. B. Park, and Y. H. Choi, "Adaptive neural sliding mode control of nonholonomic wheeled mobile robots with model uncertainty," IEEE Transactions on Control Systems Technology, vol. 17, no. 1, pp. 207-214, 2009.

[7] C. Guan and S. Pan, "Adaptive sliding mode control of electrohydraulic system with nonlinear unknown parameters," Control Engineering Practice, vol. 16, no. 11, pp. 1275-1284, 2008.

[8] K. Hasan, "Non-singular terminal sliding-mode control of DCDC buck converters," Control Engineering Practice, vol. 21, no. 3, pp. 321-332, 2013.

[9] B. Sencer, T. Mori, and E. Shamoto, "Design and application of a sliding mode controller for accurate motion synchronization of dual servo systems," Control Engineering Practice, vol. 21, no. 11, pp. 1519-1530, 2013.

[10] M. F. Rahmat, A. R. Husain, K. Ishaque, Y. M. Sam, R. Ghazali, and S. Md Rozali, "Modeling and controller design of an industrial hydraulic actuator system in the presence of friction and internal leakage," International Journal of Physical Sciences, vol. 6, no. 14, pp. 3502-3517, 2011.

[11] A. Ferrara and M. Rubagotti, "A sub-optimal second order sliding mode controller for systems with saturating actuators," IEEE Transactions on Automatic Control, vol. 54, no. 5, pp. 10821087, 2009.

[12] I. Eker and Ş. A. Akınal, "Sliding mode control with integral augmented sliding surface: design and experimental application to an electromechanical system," Electrical Engineering, vol. 90, no. 3, pp. 189-197, 2008.

[13] S. H. Qaiser, A. I. Bhatti, M. Iqbal, R. Samar, and J. Qadir, "Estimation of precursor concentration in a research reactor by using second order sliding mode observer," Nuclear Engineering and Design, vol. 239, no. 10, pp. 2134-2140, 2009.

[14] M. L. Corradini and G. Orlando, "Linear unstable plants with saturating actuators: robust stabilization by a time varying sliding surface," Automatica, vol. 43, no. 1, pp. 88-94, 2007.

[15] S. Choi, D. Park, and S. Jayasuriya, "A time-varying sliding surface for fast and robust tracking control of second-order uncertain systems," Automatica, vol. 30, no. 5, pp. 899-904, 1994.

[16] A. Sivert, F. Betin, A. Faqir, and G. A. Capofino, "Robust control of an induction machine drive using a time-varying sliding surface," in Proceedings of the IEEE International Symposium on Industrial Electronics (IEEE-ISlE '04), pp. 1369-1374, IEEE, May 2004.

[17] U. Metin, G. Salamci, and T. Serdar, "Sliding mode control design with time-varying sliding surfaces for a class of nonlinear systems," in Proceedings of the IEEE International Conference on Control Applications, pp. 996-1001, IEEE, Piscataway, NJ, USA, 2006.

[18] N. B. Almutairi and M. Zribi, "Sliding mode control of coupled tanks," Mechatronics, vol. 16, no. 7, pp. 427-441, 2006. 


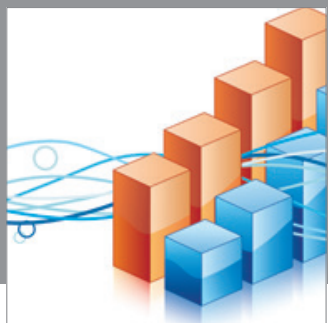

Advances in

Operations Research

mansans

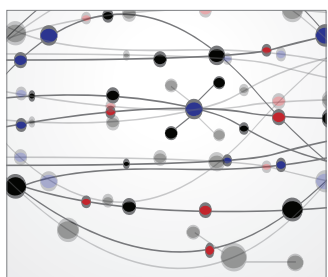

The Scientific World Journal
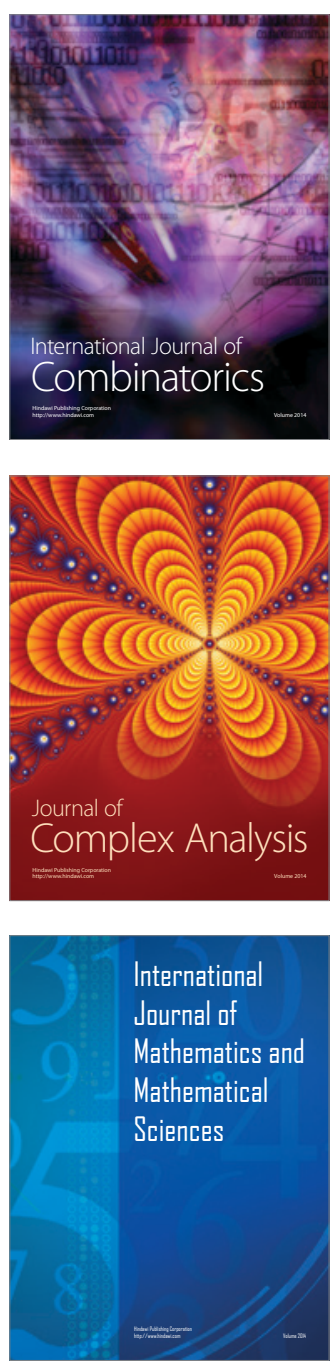
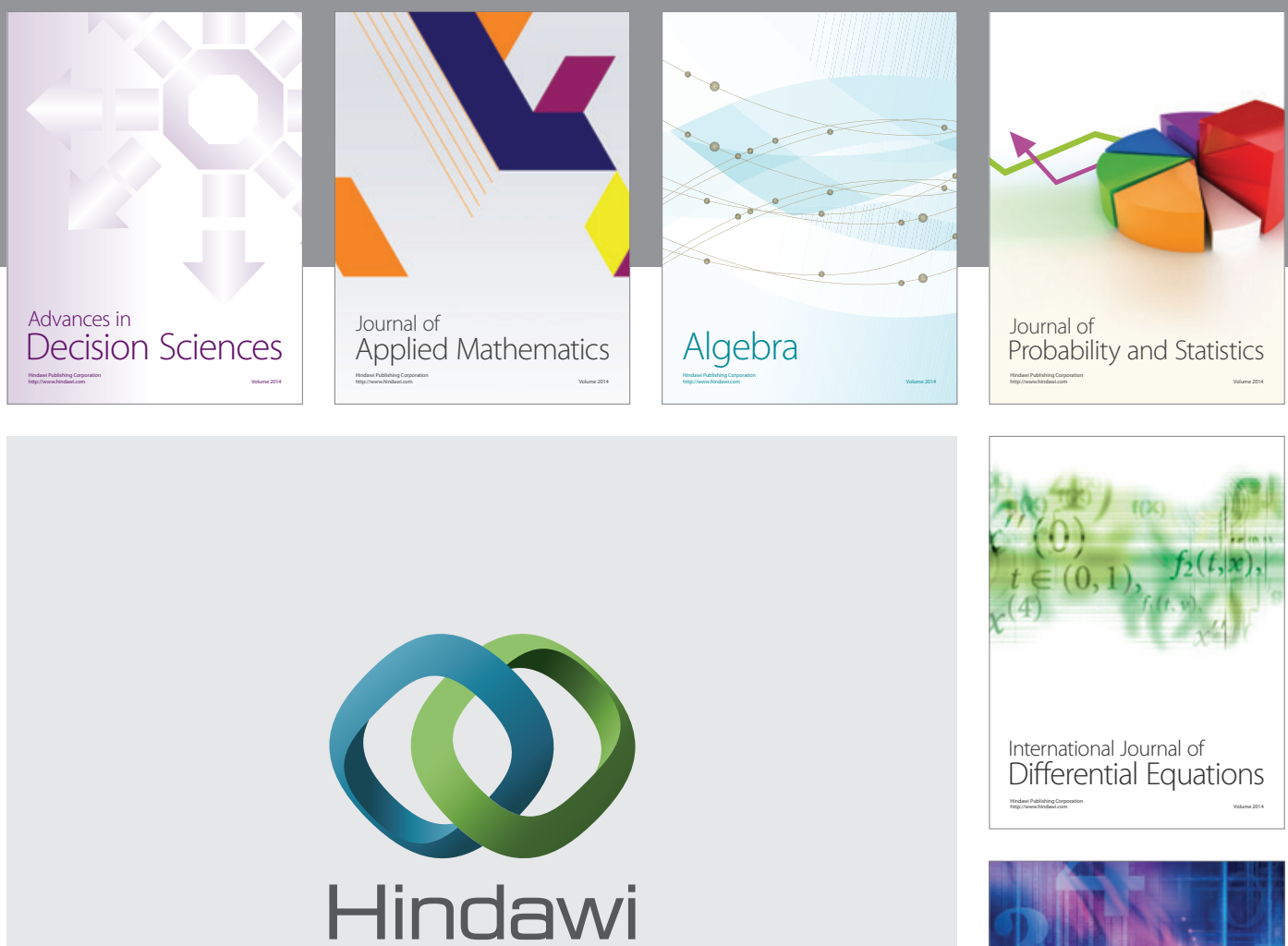

Submit your manuscripts at http://www.hindawi.com
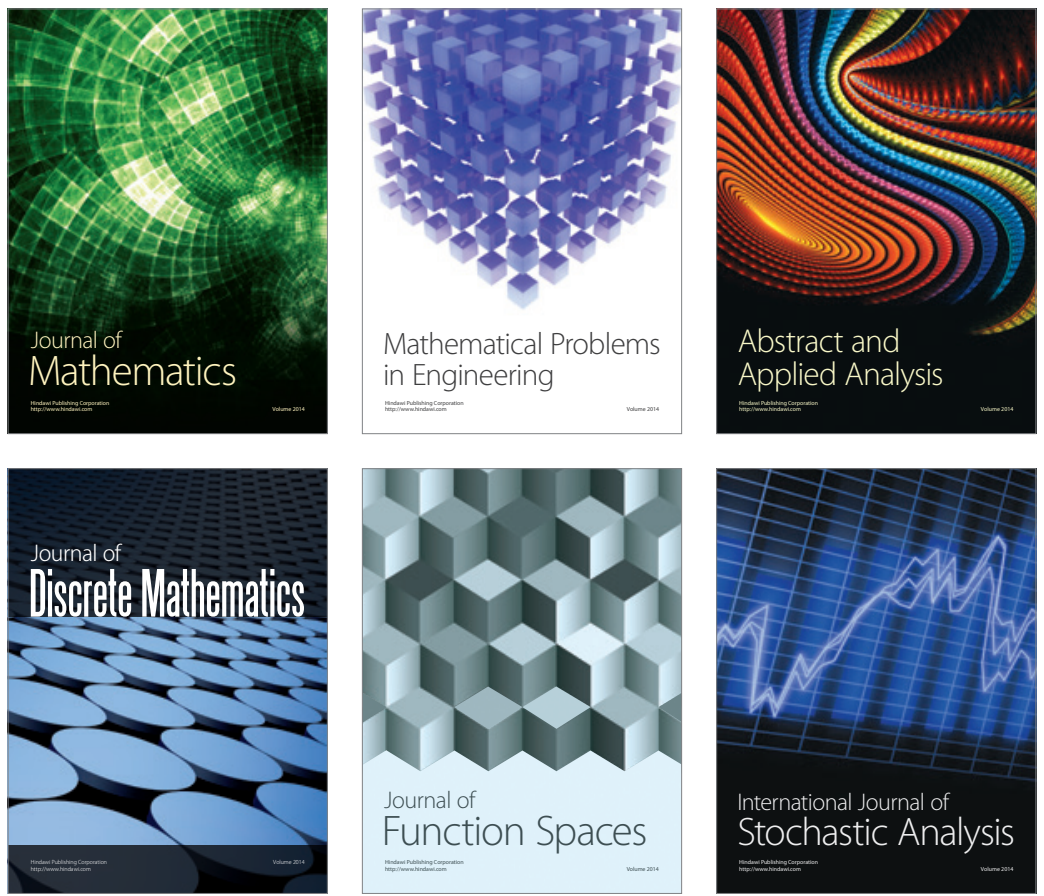

Journal of

Function Spaces

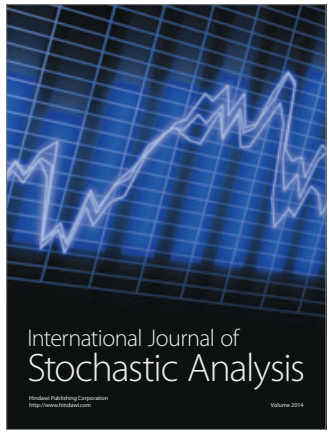

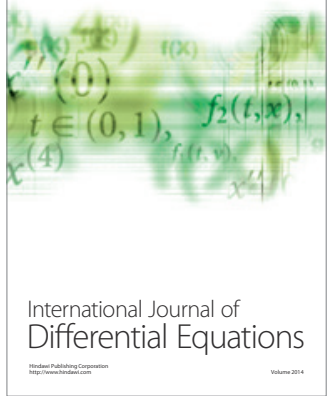
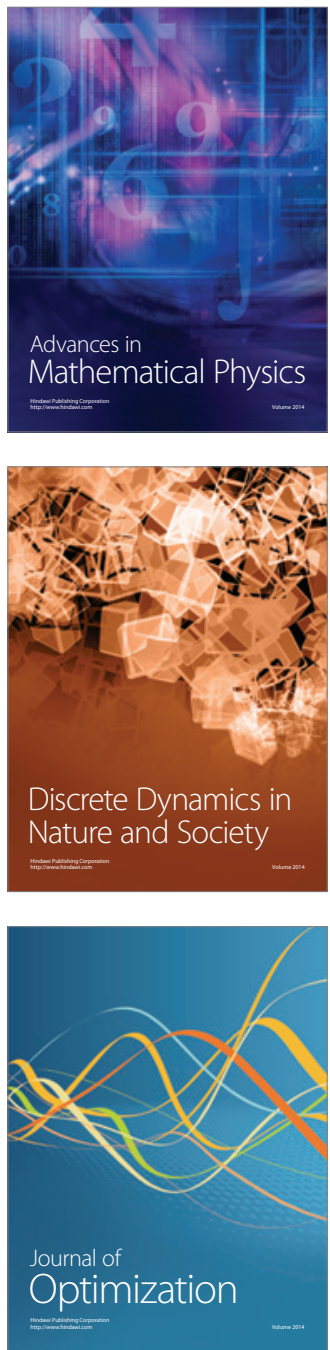